\title{
Standards-Based Grading in a Thermodynamics Course
}

\author{
https://doi.org/10.3991/ijep.v7i1.6472 \\ Scott L. Post \\ Lincoln Agritech LTD, Lincoln, New Zealand \\ scottlpostegmail.com
}

\begin{abstract}
Standards based grading is a formal assessment mechanism that tests for student achievement of specified learning objectives, or standards. Standards-Based-Grading has been gaining in popularity in K-12 education, and also has been seeing increased use in higher education, though it has only recently been used in engineering education. This paper describes how StandardsBased Grading was implemented in a second-semester Thermodynamics course. A total of eleven learning objectives were specified for the course. In this implementation of Standards-Based Grading, all assessments are done on a pass-fail basis. That is to say, there is no partial credit given. Once a student passes an assessment, usually given in the form of a quiz, on a given learning objective, it is assumed the student has mastered that concept and is not tested on it again. Students are allowed to re-test on particular objectives if they do not pass them on the first try. The final exam serves as a last chance for students to pass any objectives they did not complete earlier in the semester. The learning objectives can be mapped to student outcomes such as those required for accreditation without having to generate a separate set of data outside the normal course grading.
\end{abstract}

Keywords-Engineering education, Accreditation, Engineering students

\section{Introduction}

There have been only a very few publications on the use of standards-based education in engineering courses, including one outlining the use of the method in a materials science course [1] one for a fluid mechanics course [2], and one for project design courses [3]. This paper expands on the limited literature by demonstrating how standards-based grading could be used in a thermodynamics course. The motivations for standards-based grading are given by Post [2]. To summarize they are:

1. Remove arbitrariness and inconsistency from grading [4]

2. Reduce time in grading

3. Make grading and expectations clear to students

4. Improve students learning and understanding by focusing their efforts on successfully completing big picture tasks

The efficacy of active learning activities [5] and cooperative learning strategies [6$8]$ has been demonstrated convincingly in the literature. So how should grading being 
conducted, in light of the research showing the efficacy of active and cooperative learning? We can broadly divide grading strategies into two types of assessments: formative and summative. Formative assessments can be thought of as a loop, where "students and teachers focus on a learning target, evaluating current student work against the target, act to move the work closer to the target, and repeat [9]." Formative assessments provide feedback not just to the student, but also to the instructor. They inform the instructor of which material the students are having difficulty with and should be covered further. Summative assessments are typically performed only at the end of a particular instructional module [10]. In summative grading, a weightedaverage of student scores on a diverse set of assignments is added together to arrive at a final grade that is supposed to assess students' performance in the course. The traditional method to assess student performance in STEM courses is a summative scorebased grading system [11]. In summative grading, it is common to measure student achievement on an assignment based on how many "points" they obtain, but the point is not a well-defined unit of measurement. The arbitrariness of points is illustrated in that its value changes from instructor to instructor, and in fact can even change for a single professor from term to term if he/she does not use rubrics or another method to assure grading consistency.

The common use of a 100-point grading system gives the illusion of precision that does not exist, and grade cut-off scores are not usually linked directly to mastery of specific subject matter or skills, but rather to arbitrary decile levels such as 90/80/70 [12]. Further there is not agreement on how to translate points to grades. More importantly than grades, there is the issue of how to relate points to learning objectives and measures of student learning. "Validity, sampling adequacy, item quality, marking standards, marking reliability and measurement error generally are all significant variables that produce an underlying softness in the basic data that typically goes unrecognized [12]." In fact, "research indicates that the score a student receives on a test is more dependent on who scores the test and how they score it than it is on what the student knows and understands [13]."

The goal of Standards-Based Grading (SBG) is to measure a student's progress towards achievement of a standard, and thus to show what students are able to do. Students have multiple opportunities to demonstrate their achievement of the standard, and the final grade is based on the student's overall mastery of the standard by the end of the term, not a weighted average of material throughout the term. Standards-Based Grading can also help instructors to more clearly communicate to the students exactly what they will be expected to know and demonstrate on assessments. SBG aims to establish strong connections between assessments (and grades) and course objectives and provide a tool for program assessment $[11,12]$. The four main challenges facing an instructor who wishes to use SBG are [12]:

- Coming to grips with the concept of a standard

- Determining how to set standards

- Communicating standards to students and colleagues

- Becoming proficient in the use of standards 
SBG was first developed in the 90s [11]. Very little information has been published on the use of Standards-Based Grading (SBG) in engineering courses. Recently there have been examples published of how to do this for a limited number of courses [1-3], which can serve as a template for implementing SBG in other engineering courses. General publications on SBG include the book by Marzano [10]. Sadler [12] puts forth the arguments for why students should be evaluated using Standards-Based Grading as:

1. "Students deserve to be graded on the basis of the quality of their work alone, uncontaminated by reference to how other students in the course perform on the same or equivalent tasks, and without regard to each student's previous level of performance."

2. "At the point of beginning a course of study, students deserve to know the criteria by which judgments will be made about the quality of their work."

The term "Standards-Based Grading" has been used throughout this work as that term is used in the literature for similar such grading systems, though Sadler points out the term "criteria-based assessment" may be more accurate, as standards refer to the levels considered adequate or inadequate, while criteria refers to the properties of achievement we are assessing [12]. Standards-Based Grading aims to establish a framework that provides more consistent evaluation of student achievement from instructor to instructor. SBG would allow for comparison of student achievement across different instructors teaching multiple sections of the same course at a single institution, and also for measures of student achievement that can be easily compared across different institutions.

\section{Implementation}

Since the thermodynamics course was primarily a calculation-based course, it was decided to use a 2-point, or binary, scale in assessing students' completion of objectives. Sadler writes that many "educational outcomes cannot be assessed as dichotomous states, although the competency assessment movement predominantly adopts that perspective." 12 Because most of the objectives for this thermodynamics course were constructed in terms of students' ability to perform calculations, it was deemed appropriate to use the binary scale for this course. In other words, all objectives were graded on a pass/fail basis, with no partial credit given. An objective was considered to be passed when the student obtains a numerical answer within $+/-2 \%$ of the instructor's calculated value, reported to 3 significant digits, and a valid solution technique is used. Objectives were typically assessed with 30-minutes quizzes, and on the final exam students could attempt any objectives they had not yet passed. A whole-letter grading system is used at the university where this example of standards based grading was implemented. The relationship between student achievement of course objectives and their final grades is as follows:

Completing 10 or more course objectives results in a grade of $\mathrm{A}$.

Completing 9 of 11 course objectives results in a grade of $\mathrm{B}$. 
Completing 8 of 11 course objectives results in a grade of C. Completing 7 of 11 course objectives results in a grade of D. Completing 6 or fewer course objectives results in a grade of $\mathrm{F}$.

The 11 course objectives were:

1. Otto Cycle - Calculate $P \& T$ at each state $\&$ h given $C R, Q$, and initial conditions

2. Diesel Cycle - Calculate $P \& T$ at each state $\&$ h given $C R, Q$, and initial conditions

3. Brayton Cycle - Calculate P \& $\mathrm{T}$ at each state \& h given PR, Q, and initial conditions

4. Rankine Cycle - Calculate P \& T at each state \& h given $\mathrm{P}_{\max }, \mathrm{Q}$, and initial conditions

5. Refrigeration Cycle - Calculate $\mathrm{P}, \mathrm{T}, \& \mathrm{~h}$ at each state $\&$ b given conditions

6. Select Working fluid for an ORC - Select from a list of available refrigerants

7. Ideal Gas Mixture - Calculate properties of an ideal gas mixture

8. Psychrometrics - Calculate properties of a humid air mixture

9. Combustion - Balance a combustion reaction and calculate adiabatic flame temperature

10. Teamwork - Group completes $70 \%$ of Homework problems correctly

11. Contemporary Issues - Group successfully completes presentation on selected topic (selected from Ethanol, Electric Cars, Fuel Cell Cars, Solar Power, Wind Power, or Carbon sequestration)

While the $70 \%$ threshold for completing homework problems is arbitrary, it was based on past experience of what was reasonable expectation of the students. It also remarkable how students adjust their efforts to meet whatever arbitrary threshold is presented to them if they know that threshold will be upheld. Note the grading on homework problems is also on a pass/fail basis ( 1 or 0 points) with no partial credit given. By choosing high-level objectives (cycles) as the objectives to be assessed, this ensures the students must also be able to master the basic skills to complete these more complex tasks, so it is not necessary to add additional objectives such as ideal gas law, first law, second law, obtaining property values for tables (an obsolescent skill), etc. Keeping the number of objectives minimal helps keep students from feeling overwhelmed and helps keeping grading time low.

Example of the quiz problems that were given are as follows:

1. An ideal air-standard Otto cycle consists of isentropic compression from intake conditions of $300 \mathrm{~K}$ and $1.0 \mathrm{bar}$, constant volume heat addition of $1450 \mathrm{~kJ} / \mathrm{kg}$, followed by isentropic expansion, and then the air is exhausted at atmospheric pressure in a constant-volume process. Assuming constant specific heats, compute the pressure and temperature for each state in the cycle, sketch the process on a P-V diagram, and compute the $1^{\text {st }}$ law thermodynamic efficiency for the cycle. The compression ratio is 10.8 .

2. An ideal air-standard Diesel cycle consists of isentropic compression from intake conditions of $300 \mathrm{~K}$ and $1.0 \mathrm{bar}$, constant pressure heat addition of $1600 \mathrm{~kJ} / \mathrm{kg}$, followed by isentropic expansion, and then the air is exhausted at atmospheric pres- 
sure in a constant-volume process. Assuming constant specific heats, compute the pressure and temperature for each state in the cycle, sketch the process on a P-V diagram, and compute the $1^{\text {st }}$ law thermodynamic efficiency for the cycle. The compression ratio is 22.0 .

3. An ideal air-standard Brayton cycle consists of isentropic compression from intake conditions of $300 \mathrm{~K}$ and $1.0 \mathrm{bar}$, constant pressure heat addition of $1400 \mathrm{~kJ} / \mathrm{kg}$, followed by isentropic expansion through a turbine to atmospheric pressure. Assuming constant specific heats, compute the pressure and temperature for each state in the cycle, sketch the process on a P-V diagram, and compute the $1^{\text {st }}$ law thermodynamic efficiency for the cycle. The compressor pressure ratio is 40 .

4. An ideal Rankine cycle consists of isentropic compression from saturated liquid at $20 \mathrm{kPa}$ to compressed liquid at $15 \mathrm{MPa}$, constant-pressure heating to super-heated steam at $800{ }^{\circ} \mathrm{C}$ and isentropic expansion through a turbine back down to $20 \mathrm{kPa}$. Calculate the efficiency of the cycle and also determine the pressure, temperature, quality, and enthalpy at each state in the cycle.

5. An ideal Refrigeration cycle with R134a as the working fluid consists of isentropic compression from saturated vapor at $-10^{\circ} \mathrm{C}$, constant-pressure heat rejection in the condenser at $34^{\circ} \mathrm{C}$, constant-enthalpy pressure loss across a throttle valve, and constant-pressure heat absorption in the evaporator. Calculate the coefficient of performance of the cycle and also determine the pressure, temperature, quality, and enthalpy at each state in the cycle.

6. An Organic Rankine Cycle is to be built for a geothermal plant in a location where the environment temperature is usually around $10{ }^{\circ} \mathrm{C}$. The maximum temperature of the working fluid is $200^{\circ} \mathrm{C}$. The minimum pressure in the system must be just above atmospheric, but as close to atmospheric as possible. Select a suitable working fluid for the ORC from the list provided and justify your choice.

7. A fuel mixture contains $70 \% \mathrm{H}_{2}, 25 \% \mathrm{CH}_{4}$, and $25 \% \mathrm{C}_{8} \mathrm{H}_{8}$ on a volume basis. Find the mass fractions of each of the three components, and the density of the gaseous fuel mixture at 1 bar and $300 \mathrm{~K}$.

8. Calculate the adiabatic flame temperature for ethane $\left(\mathrm{C}_{2} \mathrm{H}_{6}\right)$ burning in air at 298 $\mathrm{K}$ and $1 \mathrm{~atm}$, assuming complete combustion and constant specific heats.

9. Air at $40{ }^{\circ} \mathrm{C}, 1 \mathrm{bar}$, and $10 \% \mathrm{RH}$ goes through an evaporative cooler, and the outlet air is cooled to $27^{\circ} \mathrm{C}$. Find (a) the relative humidity at the outlet, and (b) the amount of water added $\left(\mathrm{kg} \mathrm{H}_{2} \mathrm{O}\right.$ per $\mathrm{kg}$ of air).

Generally three chances were given to pass each objective - an initial quiz, a later quiz, and the final exam. As new objectives were presented and tested, questions on the previous objectives were included in the quiz for those students who still needed to pass them. One of the advantages of Standards-Based Grading, as it provides realtime feedback to the instructor. If none or very few of the students pass an objective, it signals to the instructor that more time in lecture should be devoted to that topic before the next assessment of that objective. Whereas in the traditional point-based system, the awarding of partial credit for incomplete work could lead to a course average on a score that indicates acceptable student performance, while masking the fact that only a small number of students in the course had mastered the concept. 
Teamwork is an important part of the course. The class is divided into teams of 3-4 students each for the homework and project. There is a great deal of literature showing that students learn more effectively in teams than they learn on their own $[7,8,13,14]$. At the end of the semester students were also allowed to evaluate their teammates to encourage accountability. Among their other findings, Felder and Brent [13] recommend that team sizes are 3-4 students, to collect one assignment per group, to have the instructor select the groups, and not to assign grades on a curve, so that students are given incentive to help each other. The goal is to create positive interdependence and individual accountability. The instructor selects the teams.

\section{Objective Results}

The final results of student achievement of objectives for the semester are shown in Table 1. There were a total of 23 students. It can be seen that on the calculation problems the pass rate was quite high, as desired. The pass rates were higher on objectives presented earlier in the course. This could be either because those objectives were based on more basic material as the more advanced problems presented later in the course built on that earlier material and were more complex. Alternatively, it could be because the students had more time over the course of the term to digest and work on the objectives they were initially tested on at the beginning of the term. The students correctly completed $78 \%$ of the homework problems, with $67 \%$ of the groups attaining at least $70 \%$ correct to pass the specified objective. The class-average GPA of 3.2 on a 4.0 scale was higher than previous experience with the course (GPA of 2.9).

Table 1. Pass rate of individual learning objectives in a Thermodynamics Course

\begin{tabular}{|l|c|}
\hline \multicolumn{1}{|c|}{ Objective } & Pass Rate \\
\hline Otto Cycle & $96 \%$ \\
\hline Diesel Cycle & $100 \%$ \\
\hline Brayton Cycle & $100 \%$ \\
\hline Rankine Cycle & $96 \%$ \\
\hline Refrigeration Cycle & $74 \%$ \\
\hline Psychrometrics & $87 \%$ \\
\hline Ideal Gas Mixture & $61 \%$ \\
\hline Select ORC working fluid & $83 \%$ \\
\hline Combustion reaction & $78 \%$ \\
\hline
\end{tabular}

\section{Survey Results}

The same two questions as in the paper on SBG in the materials science course [1] were asked to the students in an end of semester survey. Siniawski's results indicated that the vast majority of the students agreed that Standards-Based Grading is more conducive to learning $(89 \%)$ and that they prefer standards-based grading $(86 \%)$. The 
results of a similar survey in the current work were much less positive. Students were asked the following two questions:

1. Is the standards-based grading system more conducive to learning than traditional, summative score-based grading?

2. Do you prefer standards-based grading to traditional grading?

In this study of the thermodynamics course, for question \#1 only $38 \%$ of the students responded with "Strongly Agree" or "Agree" on a 5-point Likert scale, and on question \#2, 51\% responded positively. In the author's previous use of SBG in a fluid mechanics course, for question \#1 only $38 \%$ of the students responded positively, and on question \#2 only $28 \%$ responded positively. ${ }^{2}$ Since this is the first time the students were encountering SBG at Bradley University, it may have been uncomfortable for them to adapt to a grading system to which they were not familiar and unprepared to encounter. An important difference between the current work and that of Siniawski et al. is that they used a 4-point scale to assess student completion of objectives, while students complained primarily about the 2-point scale used in the current work.

Examples of student comments on the surveys are:

- "If you understand the concept but make a small error you get the whole question wrong; I don't believe this reflects the knowledge of the student"

- "Liked the idea behind it, but was very frustrated when other students passed objectives because they "stumbled across" the right number, but failed to completely understand the process, while sometimes I got the "wrong number" but understood the process.

- "It makes the goals required much more straightforward. It also eliminates the dependency of your grade on how well everyone else does or the professor's grading practice."

- "I preferred this style of grading for this class due to each objective being only one thing to obtain it."

\section{Conclusions}

This paper demonstrates how Standards-Based Grading can be used in an undergraduate engineering thermodynamics course. The use of Standards-Based Grading in an engineering course rests on the assumption that "Completion of each task (even after multiple attempts, if necessary) is taken as evidence of achievement of the relevant objective [12]." While there are potential issues with any grading system, it is believed that SBG provides a better assessment of student achievement than traditional summative-score systems that use an arbitrary point system. This study follows the philosophy of Sadler, "Whether the actual path of learning is smooth or bumpy, and regardless of the effort the student has (or has not) put in, only the final achievement status should matter in determining the course grade [15]." The advantages of SBG are that it provides better feedback to the instructor on student performance, improves student achievement of learning objectives [2], it can reduce time in grading com- 
pared to traditional score-based systems [11], and can also be directly used in showing student achievement of performance indicators of Student Outcomes for accreditation without the need for extraneous bookkeeping.

\section{References}

[1] M.T. Siniawski, A.R. Carberry, and J.D. Dionisio, Standards-Based Grading: An Alternative to Score-Based Assessment. Proceedings of the ASEE Pacific-Southwest Regional Conference, 2012.

[2] S. L. Post, Standards-Based Grading in a Fluid Mechanics Course. American Society for Engineering Education Annual Conference Paper ID \#8417, 2014.

[3] S. A. Atwood \& M. T. Siniawski, Using Standards-based Grading to Effectively Assess Project-based Design Courses. American Society for Engineering Education Annual Conference Paper ID \#8810, 2014.

[4] R. Wormeli, Fair Isn't Always Equal: Assessing and Grading in the Differentiated Classroom. Stenhouse. Portland, Maine, 2006.

[5] M. Prince, "Does Active Learning Work? A Review of the Research," Journal of Engineering Education, 93(3), pp. 223-231, 2004. https://doi.org/10.1002/j.21689830.2004.tb00809.x

[6] K.A. Smith, "Cooperative Learning: Effective Teamwork for Engineering Classrooms," Frontiers In Education Conference Proceedings. Atlanta, GA, 1995. https://doi.org/10.1109/fie.1995.483059

[7] D. W. Johnson, R. T. Johnson, and K. A. Smith, Cooperative learning: Increasing college faculty instructional productivity." ASHE-ERIC Report on Higher Education. Washington, DC: The George Washington University, 1991.

[8] D. W. Johnson, R. T. Johnson, and K. A. Smith, Active learning: Cooperation in the college classroom. Edina, MN: Interaction Book Company, 1991.

[9] S. Brookhart, and A. Nitko, Assessment and Grading in Classrooms. Pearson Education, 2007.

[10] R.J. Marzano, Formative Assessment and Standards-Based Grading. Marzano Research Library. Bloomington, IN, 2010.

[11] A.R. Carberry, M.T. Siniawski, and J.D. Dionisio, Standards-Based Grading: Preliminary Studies to Quantify Changes in Affective and Cognitive Student Behaviors. Proceedings of the 2012 IEEE Frontiers in Education Conference (FIE), 2012. https://doi.org/10.1109/FIE.2012.6462211

[12] D.R. Sadler, Interpretations of criteria-based assessment and grading in higher education. Assessment \& Evaluation in Higher Education. Vol. 30, No. 2, pp. 175-194, 2005. https://doi.org/10.1080/0260293042000264262

[13] R.M., Felder, and R. Brent, "Cooperative Learning in Technical Courses: Procedures, Pitfalls, and Payoffs." Report to the National Science Foundation. ERIC Document Reproduction Service No. ED 377 038, 1994.

[14] P. Heller, and M. Hollabaugh, "Teaching problem solving through cooperative grouping. Part 2: Designing problems and structuring groups." American Journal of Physics, 60(7), pp. 637-644, 1992. https://doi.org/10.1119/1.17118

[15] D.R. Sadler, Three In-Course Assessment Reforms to Improve Higher Education Learning Outcomes. Assessment \& Evaluation in Higher Education, 1-19, 2015. 


\section{Author}

Scott L. Post is with Lincoln Agritech LTD, Lincoln, New Zealand (scottlpost@gmail.com).

Article submitted 30 November 2016. Published as resubmitted by the author 13 January 2017. 